\title{
Choice between shock-free times in concurrent avoidance schedules
}

\author{
PAUL LEWIS, LAURIE MOON, and LARRIE HUTTON \\ Ohio University, Athens, Ohio 45701
}

\begin{abstract}
Following a shaping procedure, pigeons' pecks were maintained on concurrent, independent variable-interval schedules in which pecks on either of two keys produced different durations of shock-free time. Shock-free times scheduled as a consequence of pecking the two keys were at different times, 3 min, $1 \mathrm{~min}$, or $10 \mathrm{sec}$. The relative rates of pecking a key increased as the relative duration of shock-free time for that key increased. Results are consistent with the view that the effects of negative reinforcement are parallel, but opposite in sign, to positive reinforcement and that shock-free time is analogous to food duration in positive reinforcement experiments.
\end{abstract}

Baum (1973b), Fantino (1973), and others have recently outlined many similarities between the variables controlling behavior in negative reinforcement procedures with those controlling behavior in positive reinforcement procedures. For example, simple schedules of negative reinforcement maintain patterns of behavior similar to the pattern maintained by the same schedule of positive reinforcement (Azrin, Holz, Hake, \& Ayllon, 1963; Dinsmoor, 1962). Shock density seems to be a fundamental variable in determining the aversiveness of a situation, just as food density seems to be a basic determinant of food-reinforced responding (Autor, 1969; Herrnstein \& Hineline, 1966; Sidman, 1962). Furthermore, the frequency of shock-free times bears the same quantitative relationship to response rates in negative reinforcement procedures that frequency of food presentation bears in positive reinforcement procedures (deVilliers, 1972; Herrnstein, 1970). The same has been found with time allocation measures of negative reinforcement in concurrent schedules (Baum, 1973b).

The duration of a positively reinforcing event has systematic effects upon behavior. Because the duration of reinforcing grain presentations has not been found to have a significant influence upon response rate in singlekey situations with pigeons (Catania, 1963), a more sensitive measure, the relative rate of responding on concurrent variable-interval schedules, has generally been employed. In this procedure, "matching" is said to occur if the relative time or relative number of responses on one key is equal, or nearly equal, to the duration of reinforcers delivered on that key. Studies that have employed the concurrent choice procedure have consistently found that the relative response rate is pre-

This research was supported in part by NIMH Grant 1R01-MH-9593-1 to Ohio University and by Grant 9308 from the Ohio University Research Committee. Reprints may be obtained from: Paul Lewis, Psychology Department, Porter Hall, Ohio University, Athens, Ohio 45701. dicted by a comparison of the respective relative reinforcement durations, although it is clear that duration of positive reinforcement is a less potent determinant of preference than relative frequency (Brownstein, 1971; Schneider, 1973; Todorov, 1973). In other words, qualitative preferences for longer durations have been found, but matching has not been found.

A concurrent schedule of food presentation identifies preferences that are not revealed by response rates on simple schedules. If positive and negative reinforcement can be subsumed under the same conceptual framework (Baum, 1973), we might expect a similar finding in the case of aversive situations. Dinsmoor (1962) found that response rates in rats did not change systematically as a function of changes in the duration of shock-free time gained as a consequence of responding, a finding that is in accord with Catania's (1963) report of indifference to food duration in pigeons on simple variable-interval schedules. On the other hand, a symmetrical law of effect implies that a concurrent schedule would show preference to be a function of the duration of shock-free time. Using a common laboratory subject (the pigeon) and response (the keypeck), the present study tested this hypothesis.

\section{METHOD}

\section{Subjects}

Three White Carneaux pigeons purchased from the Palmetto Pigeon Plant, Sumter, North Carolina, served as subjects. All three were maintained at $80 \%$ of their free-feeding body weight throughout the experiment. Subjects $\mathrm{H} 1$ and $\mathrm{H} 2$ were experimentally naive; Subject B40 had extensive experience with positive and negative reinforcement schedules.

\section{Apparatus}

A standard conditioning chamber (BRS-LVE) with translucent keys was housed in a sound-attenuating box. Two pigeon keys were centered $25 \mathrm{~cm}$ from the floor and $20.3 \mathrm{~cm}$ apart. A response of $12 \mathrm{~g}(.12 \mathrm{~N})$ closed a microswitch and activated a brief feedback relay. The food reinforcer, delivered with houselights out, consisted of 4-sec access to grain. Solid state scheduling and recording equipment was located in an adjacent room. A variable ac transformer in series with a 10-Kohm 
resistor delivered 0 - to $110-\mathrm{V}$ shocks of .3-sec duration. Shock was carried to stainless steel electrodes surgically implanted around the pigeon's pubis bone (Azrin, 1959) via a mercury commutator (Gerbrands, Inc.) mounted in the ceiling of the chamber. White masking noise was present throughout each session.

\section{Procedure}

Two subjects ( $\mathrm{H} 1$ and $\mathrm{H} 2$ ) were exposed to an extensive preliminary conditioning procedure before being introduced to the terminal conditions. This reinforcement-switching procedure took 18 sessions for Subject $\mathrm{H} 1$ and 17 sessions for Subject H2 and has been described in detail elsewhere (Lewis, Lewin, Stoyak, \& Muehleisen, 1974). Before shock was introduced, both subjects were trained on a two-component chain schedule on one key. In the initial link, pecks were reinforced on a variable interval 10-sec (VI 10-sec) schedule by production of a stimulus correlated with the terminal link; in the terminal link, 3 min long, responding was reinforced with food.

When subjects responded steadily and without long pauses, shock was gradually introduced in the initial link of the chain. Shock was delivered in the initial link at variable intervals averaging $4 \mathrm{sec}$ (VT 4-sec shock schedule). Next, food was faded out of the terminal link by gradually increasing the mean interfood interval during the terminal link. Eventually responding was maintained solely by the transition from the initial link, in, which shock was delivered, to the 3-min-long "terminal link," in which shock was absent. The length of the terminal link thus corresponded to the duration of the shock-free period (SFP) that was produced by responding, at the conclusion of which the imposed "initial link" condition was reinstated with its associated contingencies. After pecking was maintained by shock-free time alone (i.e., no food at any time), the schedule controlling access to shock-free time was increased from VI $10 \mathrm{sec}$ to VI $45 \mathrm{sec}$, with a 3-min shock-free time dependent upon meeting the requirements of the VI 45-sec schedule. During this phase, the response of Subject $\mathrm{H} 1$ declined precipitously, and, for this subject only, the voltage was increased to $110 \mathrm{~V}$. Shock was $90 \mathrm{~V}$ for Subjects B40 and H2.

Unlike the other two subjects, B40, which had an extensive history of negatively reinforced keypecking, was introduced directly to the VI 10-sec schedule (no food), after which the schedule was changed to VI $45 \mathrm{sec}$ with a 3-min shock-free time. At this point, all subjects were pecking the left key, reinforced on a VI 45-sec schedule by a 3-min period of shock-free time.

After the foregoing preliminary training, all three subjects were introduced directly to the concurrent schedule. Pigeons $\mathrm{H} 2$ and $\mathrm{B} 40$ were forced to peck the right key by darkening the left key and eliminating access to the shock-free period for pecks at the left key for one session. The first condition for all three subjects was thus a concurrent VI 45-sec VI 45-sec schedule, in which independent, mutually exclusive 3-min shockfree periods (SFPs) were in effect for both keys, with access to the SFP controlled by identical, independent, simultaneously operating VI 45-sec schedules. The VI 45-sec schedules were constructed from the Fleshler and Hoffman (1962) tables. Each keypeck during the initial phase of the concurrent schedule, during which shock was delivered, operated a feedback relay momentarily.

Subjects were run daily in 50-min sessions. Before and after each session, the chamber and the response keys were darkened. In the initial (shock) period, the left key was red and the right was green. When shock-free time was obtained from either key, both keys turned white for the duration of the SFP in effect after which both the VT 4-sec shock and the red and green key colors were reinstated. Each time a subject stopped pecking one key and started pecking the other key, a 3-sec changeover delay (COD) was initiated. During the COD, the production of a SFP was prevented.

All subjects were exposed to the same four experimental conditions. Except for the last condition, all subjects were tested for approximately 20 sessions in each condition. The first condition for each subject comprised 3-min SFPs on each key. For Subjects $\mathrm{H} 1$ and B40, the second condition consisted of 3-min SFPs on the right, and 1-min on the left; the third condition consisted of 1-min SFPs on the right, and $3 \mathrm{~min}$ on the left. For Subject $\mathrm{H} 2$, the order of the second and third conditions was reversed. The fourth condition for all three subjects consisted of a 3-min SFP scheduled for right-key responses, and a 10-sec SFP for the left key. See Figure 1 for the exact order and number of sessions in each condition for individual subjects. For all birds, the relative duration of the shock-free times scheduled on each key served as the independent variable.
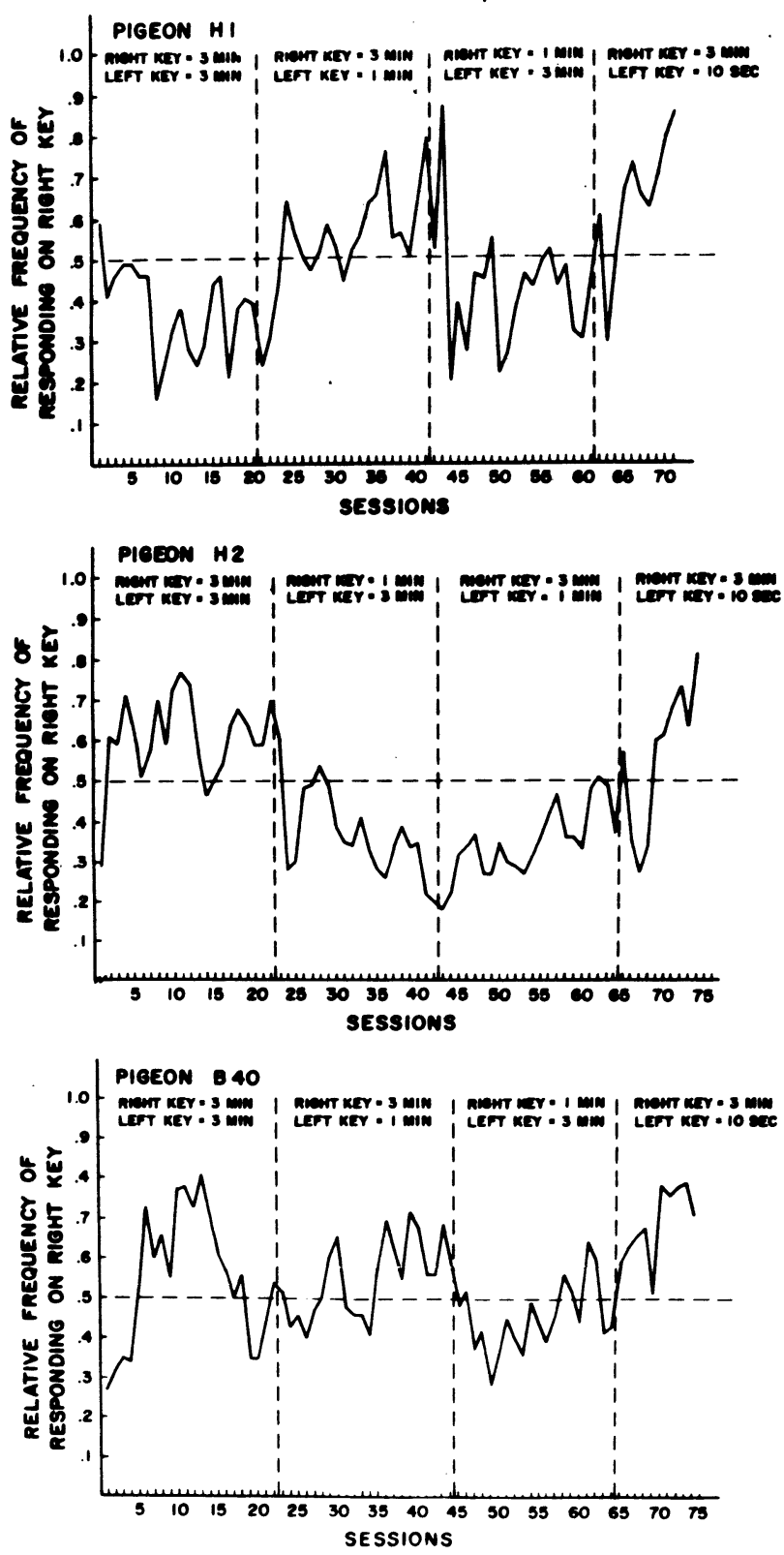

Figure 1. Relative frequency of pecking the right key for each subject in each session of the experiment is shown. Relative frequency was calculated by dividing right keypecks by the total pecks at both keys. The duration of shock-free time for each key is indicated at the top of each panel. A concurrent VI 45-sec VI 45-sec schedule controlled access to the indicated shock-free times. When not in a shock-free period, pigeons were shocked (duration $.3 \mathrm{sec}$ ) at variable intervals averaging $4 \mathrm{sec}$. 


\section{RESULTS}

The relative rates of responding are plotted in Figure 1. Pecking was maintained on the concurrent schedule in each subject for over 70 sessions. Response rates in the initial links varied from a high of $44.2 / \mathrm{min}$ for Subject B40 to a low of $1.0 / \mathrm{min}$ for Subject $\mathrm{H} 1$. The mean initial link peck rate at both keys combined over the last five sessions of each of the four conditions was determined. For Subjects $\mathrm{H} 1, \mathrm{H} 2$, and B40, the pecks/min were $4.28,10.13$, and 15.29 , respectively. All subjects virtually ceased responding during the shock-free (white-key) periods.

Relative rates were calculated by dividing pecks on the right key by total pecks on both keys. All subjects showed considerable session-to-session variability with clear biases toward one key or the other in the initial, equal-valued condition. Figure 1 shows that Subject B40 started out with a left-key bias in the first condition, shifted to favor the right key, and finally returned to the left key.

In all cases, however, the changes in preference are in accord with those predicted by matching. This was most clear in the last condition, in which the right-key 3-min SFP was clearly preferred over the $10-\mathrm{sec}$ left SFP. The changes from 1-min and 3-min SFPs to 3-min and 1-min SFPs produced smaller shifts in preference; for Subject $\mathrm{H} 2$, there appeared to be no change in preference. Changes in preference with respect to the previous condition appeared to be more reliably correlated than was a given relative rate of response with alterations in the SFP durations. The most extreme condition $(3 \mathrm{~min}$ and $10 \mathrm{sec}$ ) gave the clearest differences in relative rates.

Figure 2 shows the number of changeover responses/ min averaged over the last five sessions plotted as a function of relative rate of pecking on the right key. The changeover rates tended to be at a maximum when relative rates were near .50 ; the remainder of the points form an approximate inverted $U$.

\section{DISCUSSION}

Changes in the duration of shock-free time were related to the preference for that condition. This effect, however, appeared to be quite small except at the most extreme differences in relative reinforcement duration.

Relative rate of response did not match the relative duration of shock-free time produced by those responses. In this respect, the findings parallel those of the positive reinforcement literature in that relative magnitude of positive reinforcement has a much less potent effect upon relative response rates than does relative frequency (Schneider, 1973). Although the exact mechanism is not clear, it is possible that both of these effects are related to the discriminability of the changes in duration. This has been suggested in comparisons of reinforcer effectiveness as a function of magnitude or frequency in positive reinforcement (Schneider, 1973), in which matching was found if an appropriate "weighting" transformation was performed on the duration parameter.

The present data show that the concurrent-schedule technique can be adapted to studies of negative reinforcement. Baum (1973b) has reported a similar schedule with pigeons using a time allocation measure; the present experiment extends this to the more common keypeck, thus facilitating comparisons with experiments using positive reinforcement. Indeed, the most significant finding is that, as in positive reinforcement, relative reinforcer durations affect preference for alternatives containing those durations, but that the relative durations do not lead to matching of response rates.

On the other hand, the data are more variable than has been the usual case with positive reinforcement, even if the overall trends are quite discernible. Caution should be exercised, however, before attributing the variability solely to the differences between positive and negative reinforcement per se. While it is possible that greater variability in negative reinforcement procedures is due solely to the inherent differences between positive and negative reinforcement, other factors could be involved in the present experiment. In particular, the use of 50-min sessions with long reinforcer durations (cf. the typical 4-sec food-hopper duration) often resulted in relatively short times actually spent in the choice situation. This was especially true with the longer (3-min) SFP durations.

The data in Figure 2 are consistent with previous studies. Several authors (Brownstein \& Pliskoff, 1968; Herrnstein, 1961) have reported that pairs of alternatives that produce strong preferences. also produce low changeover rates in schedules of positive reinforcement. The approximately inverted U-shaped function when changeover rate was plotted as a function of preference in the present experiment is in accord with these

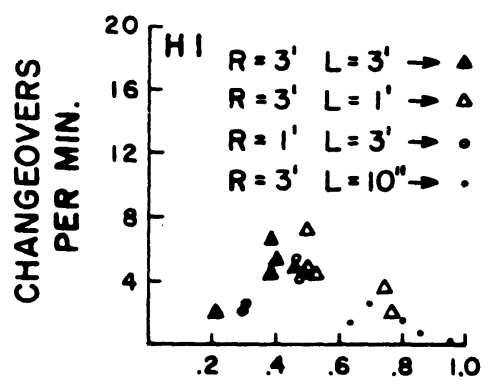

RELATIVE RATE

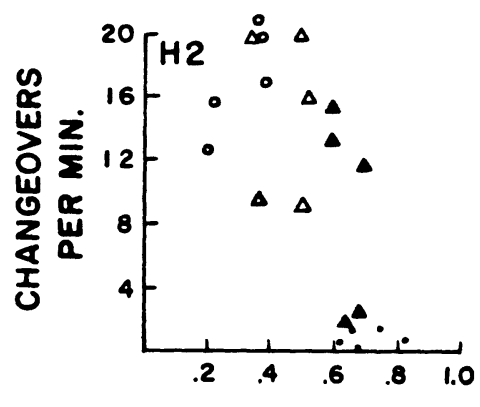

RELATIVE RATE

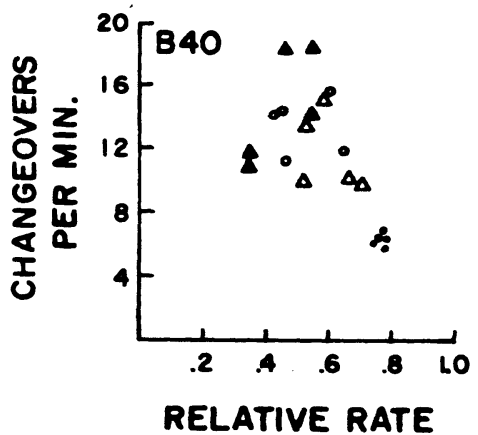

RELATIVE RATE

Figure 2. Changeover responses/min as a function of preference (relative rate of pecking on the right key). Twenty data points for each subject are shown, one for each of the last five sessions under each of the four conditions. Each axis shows data for one bird. 
earlier studies. A similar finding was reported by Baum (1973b), who used a shuttlebox time-allocation measure with pigeons on a concurrent avoidance schedule.

Although the present data do suggest a correspondence between negative and positive reinforcement, more quantitative analysis is required. It is likely that the effects of other parametric manipulations upon concurrent avoidance behavior will provide information on the extent to which data from both positive and negative reinforcement procedures can be incorporated into a symmetrical law of effect.

\section{REFERENCES}

Autor, S. M. The strength of conditioned reinforcers as a function of frequency and probability of reinforcement. In D. P. Hendry (Ed.), Conditioned reinforcement. Homewood, Ill: 1969. Pp. 127-162.

Azrin, N. H. A technique for delivering shock to pigeons. Journal of the Experimental Analysis of Behavior, 1959, 2, 161-163.

Azrin, N. H., Holz, W. C., Hake, D. F., \& Ayllon, T. Fixedratio escape reinforcement. Journal of the Experimental Analysis of Behavior, 1963, 6, 449-456.

BaUM, W. M. The correlation-based law of effect. Journal of the Experimental Analysis of Behavior, 1973, 20, 137-153. (a)

BAUM, W. M. Time allocation and negative reinforcẹment. Journal of the Experimental Analysis of Behavior, 1973, 20, 313-322. (b)

Brownstein, A. J. Concurrent schedules of response independent-independent reinforcement: Duration of a reinforcing stimulus. Journal of the Experimental Analysis of Behavior, 1971, 15, 211-214.

Brownstein, A. S., \& Pliskoff, S. S. Some effects of relative reinforcement rate and changeover delay in responseindependent concurrent schedules of reinforcement. Journal of the Experimental Analysis of Behavior, 1968, 11, 683-688.
Catania, C. Concurrent performances: A baseline for the study of reinforcement magnitude. Journal of the Experimental Analysis of Behavior, 1963, 6, 299-300.

DEVILLIERS, P. A. Reinforcement and response rate interaction in multiple random-interval avoidance schedules. Journal of the Experimental Analysis of Behavior, 1972, 18, 499-507.

Dinsmoor, J. A. Variable-interval escape from stimuli accompanied by shocks. Journal of the Experimental Analysis of Behavior, 1962, 5, 41-47.

Fantino, E. Aversive control. In J. A. Nevin (Ed.), The study of behavior. III: Scott, Foresman, 1973. Pp. 329-379.

Fleshler, M., \& Hoffman, H. S. A progression for generating variable interval schedules. Journal of the Experimental Analysis of Behavior, 1962, 5, 529-530.

HERRNSTEIn, R. J. Relative and absolute strength of response as a function of frequency of reinforcement. Journal of the Experimental Analysis of Behavior, 1961, 4, 267-272.

HerRnsteIn, R. J. On the law of effect. Journal of the Experimental Analysis of Behavior, 1970, 13, 243-266.

HerRnstein, R. J., \& Hineline, P. N. Negative reinforcement as shock-frequency reduction. Journal of the Experimental Analysis of Behavior, 1966, 9, 421-430.

Lewis, P., Lewin, L., Stoyak, M., \& Muehleisen, P. Negatively reinforced key pecking. Journal of the Experimental Analysis of Behavior, 1974, 22, 83-90.

SChNEIDER, J. W. Reinforcer effectiveness as a function of reinforcer rate and magnitude: A comparison of concurrent performances. Journal of the Experimental Analysis of Behavior, 1973, 20, 461-471.

Sidman, M. Reduction of shock frequency as reinforcement for avoidance behavior. Journal of the Experimental Analysis of Behavior, 1962, 5, 247-257.

ToDorov, J. C. Interaction of frequency and magnitude of reinforcement on concurrent performances. Journal of the Experimental Analysis of Behavior, 1973, 19, 451-458.

(Received for publication June 28, 1976.) 